\title{
Interpretation of the Magnetic Measurements of the Swarm-A Satellite over Central Europe
}

\section{PT Taylor ${ }^{1 *}$, KI Kis ${ }^{2}$, B Toronyi ${ }^{3}$, S Puszta ${ }^{4}$ and G Wittmann ${ }^{5}$}

${ }^{1}$ Geodesy and Geophysics Laboratory NASA/GSFC Greenbelt, USA

${ }^{2}$ Geophysics and Space Sciences Department, L Eötvös University, Hungary

${ }^{3}$ Department of Geodesy and Surveying, Budapest University of Technology and Economics, Hungary

${ }^{4}$ Fractal Partnership, Hungary

${ }^{5} \mathrm{MOL}$ Group, Hungary

\begin{abstract}
Our paper discusses the determination of total magnetic field anomalies derived from the Swarm-A satellite data; one of two low orbiting satellites of the three Swarm formations. This procedure requires several modifications. The first step is the conversion of the measured CDF data to the ASCII format. This step is followed for the selection of the data with $\mathrm{K}_{\mathrm{p}}$ index $\leq 1_{+}$. The anomalies are determined by the removal of the IGRF from the resulting satellite data. There are two Swarm-A data sets descending (6000) orbits and ascending (5688) orbits. For our study the descending orbits were used. The calculations next step is to difference of the two-dimensional linear field Figure 3 fitted to the Swarm-A anomalies and the anomalies given in Figure 2. These anomalies are filtered by Gaussian low-pass filter. The last step of the corrections is the remove the direct component, zero spatial frequency, from the descending orbits. The anomalies and their vertical gradients are qualitatively interpreted over Central Europe and the Pannonian Basin.
\end{abstract}

\section{Keywords}

Swarm a satellite, Magnetic anomalies, Vertical gradient

\section{Introduction}

The magnetic anomalies of the Swarm A satellite over Central Europe and the Pannonian Basin and their vertical gradients are discussed in the present paper. We wish to determine the geologic/tectonic results that can be derived from this advanced three satellite magnetic mission. The
Swarm A, B and C satellites were launched by the Rokot rocket from the Plesetsk cosmodrome on November 22, 2013. The Swarm mission is operated by the European Space Agency in their Living Planet Program.

The Swarm satellites were launched into a nearly circular orbit. The lower two fly in tandem. The

*Corresponding author: PT Taylor, Geodesy and Geophysics Laboratory NASA/GSFC Greenbelt, MD 20771, USA

Accepted: May 21, 2019; Published: May 23, 2019

Copyright: @ 2019 Taylor PT, et al. This is an open-access article distributed under the terms of the Creative Commons Attribution License, which permits unrestricted use, distribution, and reproduction in any medium, provided the original author and source are credited.

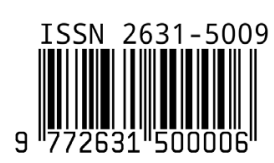

Taylor et al. Int J Astronaut Aeronautical Eng 2019, 4:029 


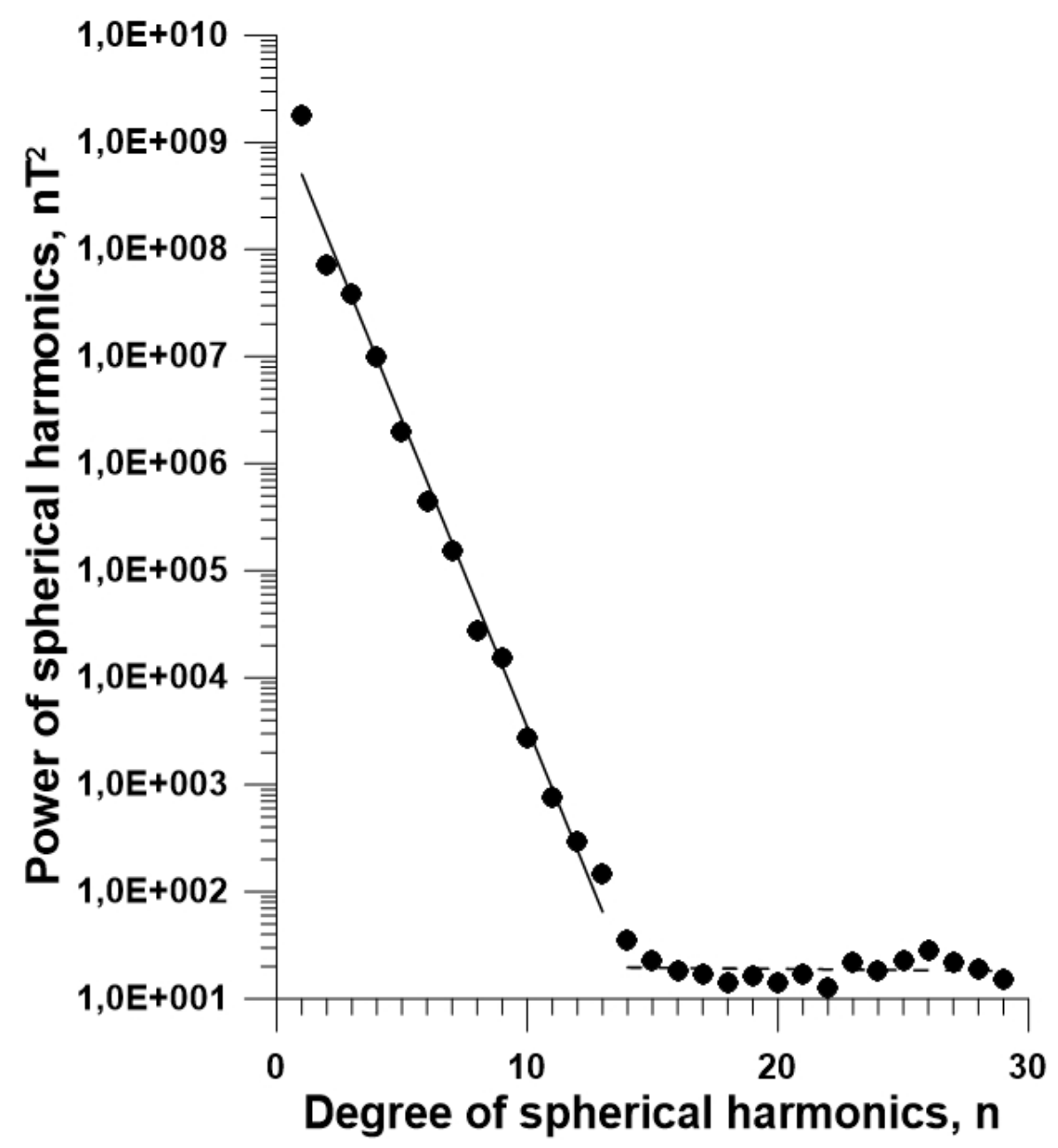

Figure 1: Logarithmic power of the spherical harmonics (spectrum) of geomagnetic field plotted versus the spherical harmonics degree $n$. The fitted solid line indicates the contributions from the core and the dashed line the crust [26].
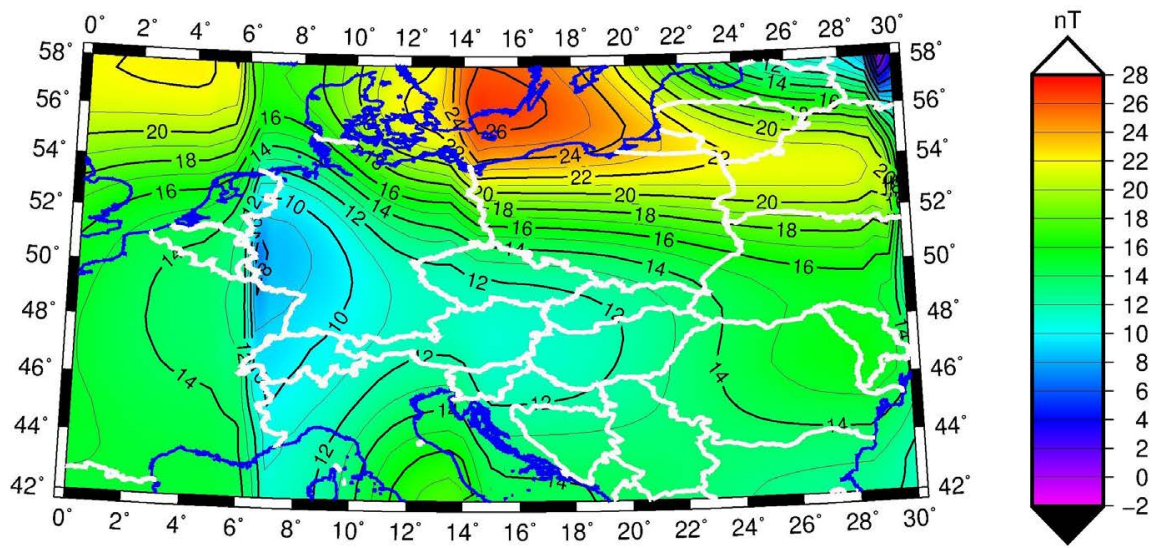

Figure 2: Swarm A total magnetic anomaly field at $450 \mathrm{~km}$ altitude over a part of Central Europe before longwavelength fields are removed. The anomalies are plotted in an Albers equal area projection. Color bar gives field in $\mathrm{nT}$.

initial altitude of Swarm A and C was $460 \mathrm{~km}$ while satellite $B$ was at $530 \mathrm{~km}$. The orbital inclination of satellites $A$ and $C$ is $87.4^{\circ}$ while the satellite $B$ is $88^{\circ}$.
The $A$ and $C$ satellites have their orbit nearly parallel with an approximate spherical separation of $1.5^{\circ}$ at the equator. There was a problem with the back- 


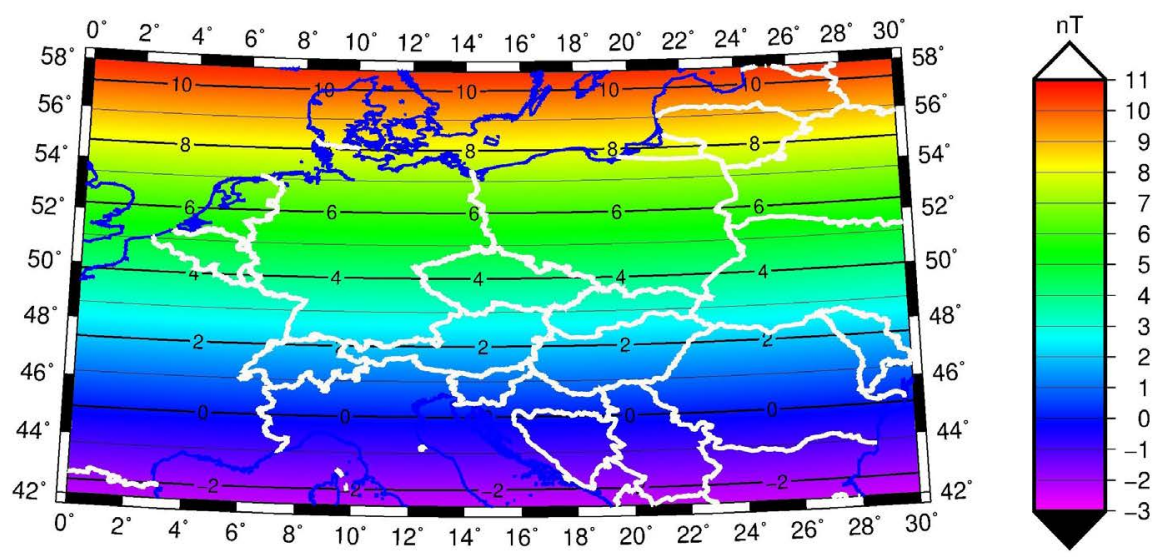

Figure 3: A two-dimensional linear magnetic field is fitted to the magnetic anomalies (of Figure 2) over a part of Central Europe. Isolines are plotted in an Albers equal area projection. Color bar gives field in nT.

up scalar magnetometer on the $C$ satellite.

The satellites have a flux gate vector magnetometer and an Overhauser scalar magnetometer. The scalar and vector magnetometers make measurements every second. One day registration of every magnetometer means 86,400 measurements. If we take an average 90 minutes for one daily revolution the registration (one file) it is more or less equivalent to 16 satellite orbits.

The interpretation of magnetic anomalies recorded at satellite-altitude has a long history. These studies were initiated by the interpretation of magnetic anomalies from Cosmos, POGOs, Magsat, Oersted, CHAMP and SAC-C satellites. In the early papers $[1,2]$ they considered satellite detected magnetic anomalies in resource exploration. They found the appropriate altitude, the required accuracy and errors of the satellite measurements required for resource evaluation. European tectonic features mapped by Magsat were presented $[3,4]$. Both detected the Tornquist-Teisseyre tectonic zone, the Kursk iron-formation, the Central Svecofennian Subprovince, the low over southern Finland, Ladoga-Gulf of Bothnia zone, the Baltic Shield [9].

\section{A Review of Previous Studies}

Previously we presented and discussed several methods for interpreting CHAMP magnetic anomalies over the Pannonian basin (e.g. [5]). The analytically determined vertical gradient and downward continuation of the magnetic anomalies were presented and may be correlated with the major tectonic shown in Figure 6, e.g., Scandinavia and major crustal shields of Russia. The inversion procedures are discussed [5] and [6]. The Laplacian and Gaussian model parameter distributions and the effect of regularization are presented [5] [6] and [7] showed the calculation of horizontal gradients and their interpretation, [8] pointed out that the source of the global magnetic anomalies was in the lithosphere. They applied the CHAMP magnetic measurements for their interpretation. The application of gradient tensors is discussed [9]. At present we are studying the same region (Figure 6) using results from Swarm.

\section{Data Processing}

The Swarm magnetic data can be found in the ESA/Swarm Level $1 B$ folder. These measurements are from the $A, B$ and $C$ satellites and are given in CDF (Content Definition File) format.

The first step in the data processing is the conversion of the CDF format to the ASCII (American Standard Code for Information Interchange) format because further computations require ASCII.

These downloaded files contain the date and time of the measurements, the spherical coordinates (latitude, longitude and spherical radius); the $X, Y, Z$ components of the magnetic field; and their errors.

These data files are used for selecting the quiet time data by using the $K_{p}$ index [32] we selected those data when $\mathrm{K}_{\mathrm{p}}$ was less than or equal to $1_{+}$. The $\mathrm{K}_{\mathrm{p}}$ indices are provided by the IAGA International Service of Geomagnetic Indices (http://isgi.unistra. fr/indices_kp.php).

The next step is the computation of the anomalies. The reference level of the main magnetic field 
is determined by using the $12^{\text {th }}$ generation of the International Geomagnetic Reference Field (IGRF) [10].

The Earth's magnetic potential field is given by the equation:

$W(r, \theta, \lambda, t)=a \sum_{n=1}^{N} \sum_{m=0}^{n}\left(\frac{a}{r}\right)^{n+1} \times\left(\mathrm{g}_{n}^{m}(t) \cos (m \lambda)+h_{n}^{m}(t) \sin (m \lambda)\right) P_{n}^{m}(\cos \theta)$,

Where $r$ is the polar distance, $\theta$ is colatitude, $\lambda$ is the polar longitude, $t$ is the time, $a$ is the Earth's mean radius $(6371.2 \mathrm{~km}), \mathrm{g}_{n}^{m}$ and $h_{n}^{m}$ are time dependent coefficients of the Gaussian expansion, $P_{n}^{m}(\cos \theta)$ is the associated Legendre function of $n$-degree and $m$-order they are normalized according to the convection of Schmidt polynomials.

The negative gradients of the potential give the $X, Y$ and $Z$ components of the magnetic field:

$$
X=\frac{1}{r} \frac{\partial w}{\partial \theta}, Y=-\frac{1}{r \sin \theta} \frac{\partial w}{\partial \lambda} \text { and } Z=\frac{\partial w}{\partial r}
$$

The total magnetic field is given by the equation

$$
T=\sqrt{X^{2}+Y^{2}+Z^{2}}
$$

Susan Macmillan (British Geological Survey) made available a FORTRAN program for the calculation of the IGRF which can be found on the IAGA home page. The FORTRAN program by Susan Macmillan (British Geological Survey) is modified according to the present requirements. Complex file systems are developed. The date, time, polar coordinates (latitude, longitude, polar distances measured from the center of the Earth) measured $X, Y$, $Z$ and $F$ components are given by the Swarm data files for every second. There are 86.400 seconds in one day file. The date and time are converted into the right format according to the requirements of the IGRF calculation. The converted date and time and the other spherical polar coordinates (latitude, longitude, polar distance) are copied into the file which calculates the IGRF. These parameters are the input data of the IGRF calculations. The field components and the total field are calculated in the right date, time and the polar point determined by the satellite. The differences of the measured field data and the calculated IGRF data determine the anomalies such as $\Delta \mathrm{X}, \Delta \mathrm{Y}, \Delta \mathrm{Z}, \Delta \mathrm{F}$.

Figure 1 illustrates the [11] [12] $R_{\mathrm{n}}$ spectrum determined from the Gaussian coefficients, that is

$$
R_{n}=(n+1) \sum_{m=0}^{n}\left(\left(\mathrm{~g}_{n}^{m}\right)^{2}+\left(h_{n}^{m}\right)^{2}\right)
$$

We fitted lines to the logarithmic power of the spherical harmonics (spectrum) from 0 to 13 and from 16 to 30 degrees, respectively. These lines show two significant ranges. The steepest line shows the contribution of the magnetic field originated from the Earth's core the other less steep line corresponds to the magnetic field originated from the Earth's crust. If we consider only the coefficients from $n=16$ we get the field originated from the crust. We applied the results of [11], [12], [26] and [33] that $n=16$ is the correct degree.

The reference field is calculated for e time and position of the measured satellite data. The $\Delta X, \Delta Y$, $\Delta Z$ and $\Delta F$ anomalies are given as the difference of
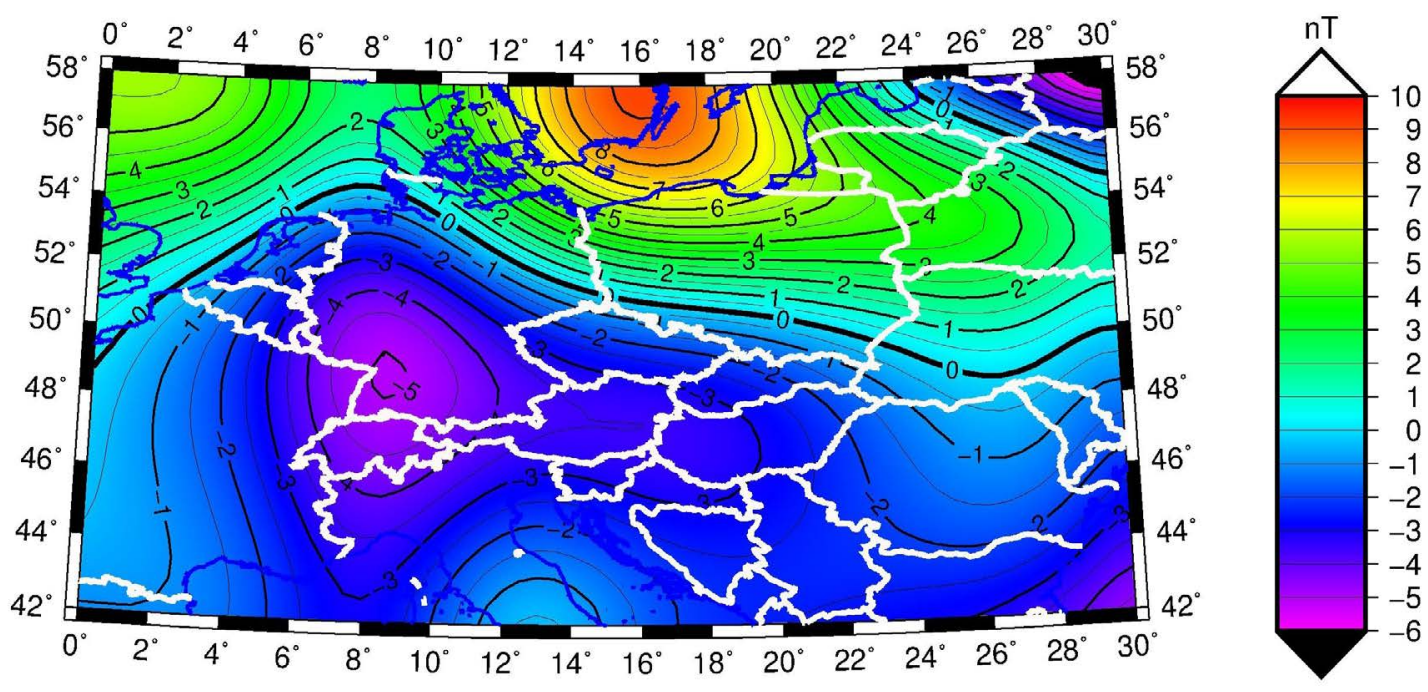

Figure 4: Total magnetic anomalies at $450 \mathrm{~km}$ altitude over Central Europe longer wavelength (IGRF) have been removed. Isolines are plotted in an Albers equal area projection. Color bar gives field in nT. 
the measured values and the IGRF. The anomalies are determined for the entire orbit.

Later the anomalies are calculated for a spherical quadrangle in a latitude band of $42^{\circ} \leq \phi \leq 58^{\circ}$ and in longitude sector of $0^{\circ} \leq \lambda \leq 30^{\circ}$. The anomalies are determined at $450 \mathrm{~km}$ altitude. Figure 2 shows resulting total magnetic field anomaly for Central Europe. Further corrections have to be applied before it can be used for interpretation.

In the next step a two-dimensional trend is fitted to the anomaly field. The two- dimensional trend is a function of the latitude $\phi$ and longitude $\lambda$ :

$$
T(\Delta \varphi, \Delta \lambda)=\mathrm{s}_{1}+s_{2} \varphi+s_{3} \lambda
$$

The two-dimensional trend is fitted by the least squares method. The coefficients of the linear trend for Central Europe (range of $42^{\circ} \leq \phi \leq 58^{\circ}$ and $0^{\circ} \leq \lambda \leq 30^{\circ}$ as it can be seen in Figure 3) are $s_{1}$ $=-36.8449 \mathrm{nT}, \mathrm{s}_{2}=0.8203 \mathrm{nT} / \mathrm{deg}$ and $\mathrm{s}_{3}=-0.00472$ $\mathrm{nT} / \mathrm{deg}$. It is obvious the linear trend is mainly a function of $\phi$. This linear trend (Figure 3) illustrates the tendency of the North-South direction of the anomalies. If we want to eliminate this tendency the values of the linear trend should be subtracted from the anomalies $002 \mathrm{E}$.

The next step is the application of the two dimensional low-pass filter [13]:

$$
s\left(r^{\prime}\right)=\pi \mathrm{d}^{2}\left(\frac{m}{36}\right)^{2} \exp \left(-\left(\left(\frac{\pi m r^{\prime}}{36}\right)^{2}\right)\right),
$$

Where $m$ is the parameter of the low-pass filter, $d$ is the sampling interval, $r^{\prime}$ is a dimensionless variable (measured in sampling interval) from the central element of the coefficients. The optimal parameter of the low-pass filter is determined after some trial and error procedures. The low-pass filter passes wavelengths longer than $1820 \mathrm{~km}$.

The next step in the data processing is separating the ascending and descending orbits. There are 11,688 orbits in our study area they are divided into 6000 descending and 5688 ascending orbits. The descending orbits are used for deriving the total magnetic field anomalies because the ascending orbits have a higher noise level [34]. states that: "The dawn passes yield a magnetic map that is different than the dusk passes," therefore we chose the quieter of the two data sets. This difference is a result of variations of the external field.

The last step of the data processing is the subtraction of the direct component (average) from the anomalies.

After the all corrections the anomaly field is be interpreted (Figure 4).

As an important part of our interpretation we calculated the vertical magnetic anomaly gradient. The numerical method for this calculation is presented [14]. The vertical gradient expresses the change in the anomalies which is caused by the variation in the magnetization of the source or the change in the depth of the source or both effects.
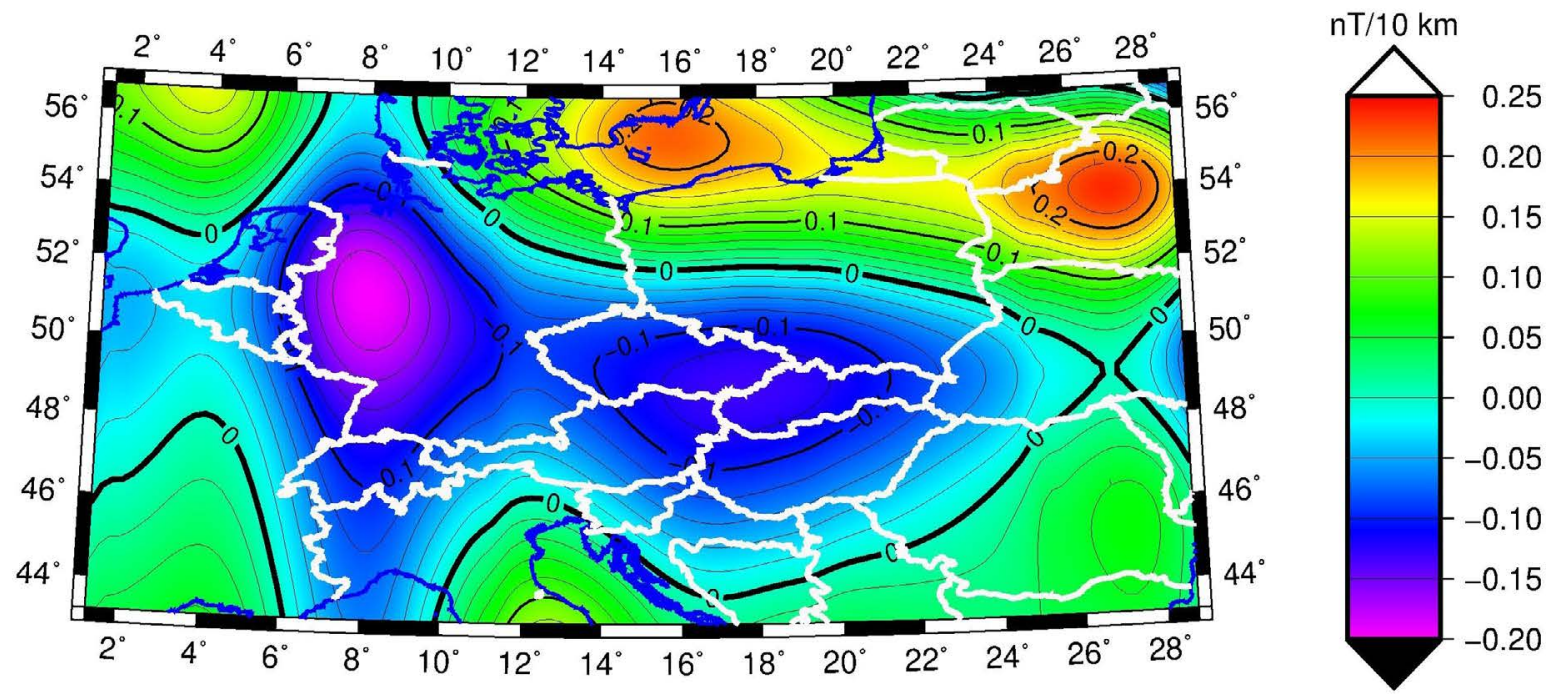

Figure 5: Vertical gradients of the total magnetic anomalies in Figure 4 over Central Europe. Isolines are plotted in an Albers equal area projection. Color bar gives field in nT/10 km. 
The scale of the vertical gradients is expressed in units of $\mathrm{nT} / 10 \mathrm{~km}$ because it results a highlighting of the magnetic sources. (The calculated vertical gradients of the anomalies will be shown in Figure 5 and Figure 8, respectively).

\section{Tectonic Interpretation}

These satellite-altitude anomalies, presented in Figure 4 clearly show the regional geological structure of Central Europe, for example the Central European relative magnetic low anomaly over Germany was shown previously by Magsat [4]. This corresponds to a thinner crust. There is also a negative magnetic anomaly over the Pannonian Basin. These relative magnetic anomalies correspond to regions of the higher heat flow. The zero isoline delineates the Tornquist-Teisseyre tectonic lineament and maps the contact between the Paleozoic European and Precambrian Russian platforms. The thickness of the crust of the European platform is $30-35 \mathrm{~km}$ while the Russian platform is $42-47 \mathrm{~km}$ thick. In the north the anomaly map shows the southern edge of the magnetic negative anomaly over Finland.

Figure 5 shows the vertical gradients [26] for our study region that expresses the tectonic structure of Central Europe, the separation the Russian platform from the European platform, the negative anomalies Germany, and the Tornquist-Teisseyre tectonic line.

Figure 6 shows the structural outline of Europe [15] is encompasses a larger territory than we present. We will discuss how these anomalies define the Central European Pannonian Basin. This basin is a back-arc basin which is surrounded by the Alpine, Carpathian and Dinaric mountains chains. The development of the Pannonian Basin is summarized by [16], [17], and [8].

The final development of the Pannonian Basin began in the late Oligocene and the early Miocene.

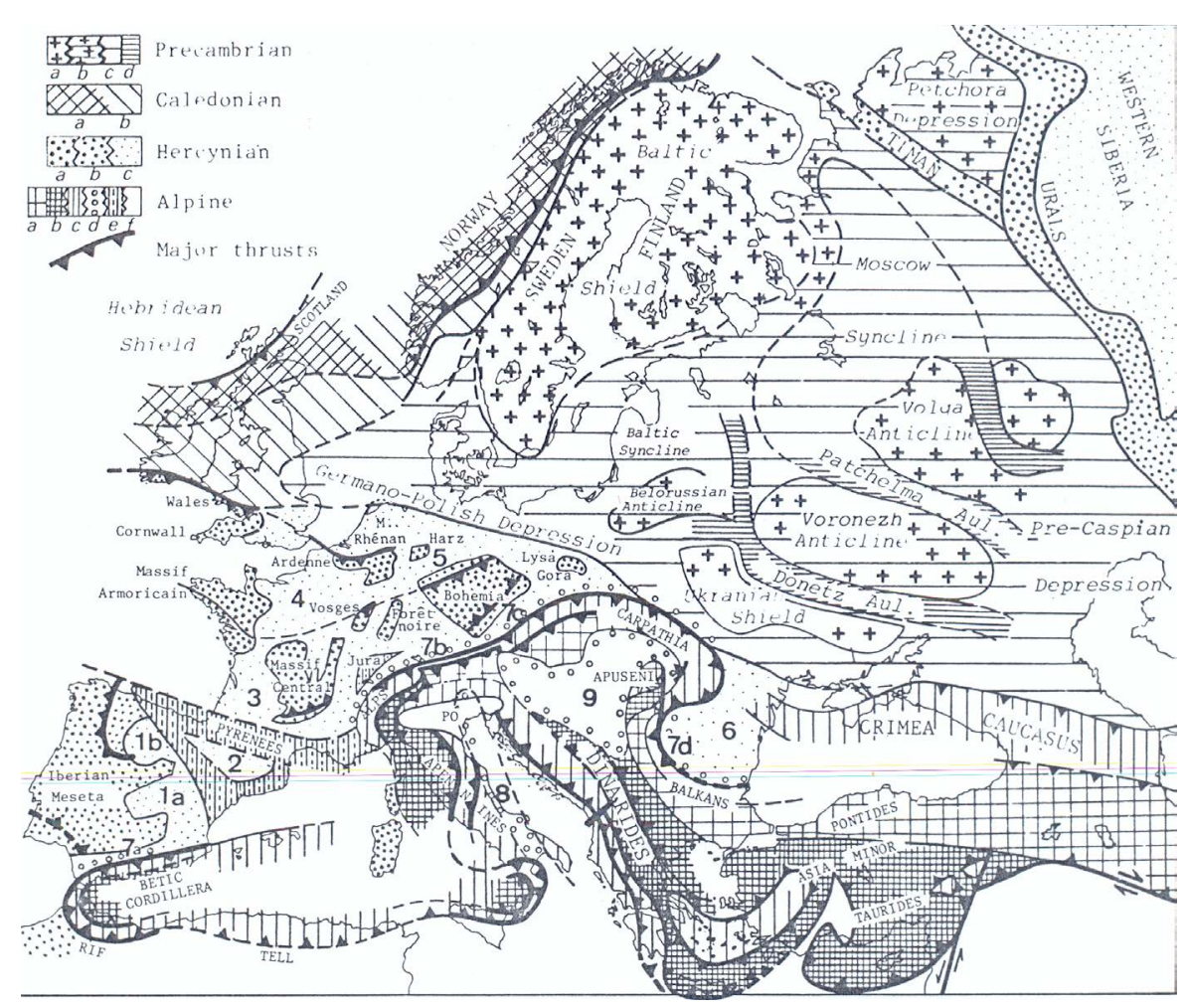

Figure 6: Structural Outline of Europe: Precambrian: a) Shields, b) Anteclises, Uplifted areas of continental platform, c) Syneclises; Depressed areas of continental platform, d) Aulacogen. Caledonian: a) Internal metamorphic zones and/or ophiolites, b) External weakly metamorphosed zones. Hercynian: a) Internal metamorphic zones, b) External zones, c) Hercynian platform. Alpine: a) Internal zones in general, b) Internal metamorphic zones and/or ophiolites, c) External zones, d)Molasse, e) Intercontinental Mountain Chains, f) Pliocene-Quaternary. 1) Castillian Basins (1a Nouvelle Castille, 1b VieilleCastille); 2) Ebre Basin; 3) Aquitaine Basin; 4) Anglo-Paris Basin; 5) Assemblage of German Basins; 6 Dacique Basin; 7) Alpine foredeep (7a Guadalquivir; 7b) Alpine foredeep proper; 7c) Peri-Carpathic foredeep; 7d) Balkan foredeep) 8) Italo-Dinaric foredeep; 9) Pannonique Basin (backdeep) [15]. 
The Pannonian Basin was mainly created by the collision of the Eurasian plate and the Adria microplate which is linked to the African plate [28].

The development of the Pannonian Basin is the consequence of the opening and closure of the Triassic-Cretaceous Neo-Tethys and Middle Jurassic-Tertiary Alpine Tethys. The basement is composed of deformed and folded Paleozoic and Mesozoic formations which are covered by less deformed sedimentary layers. These tectonic processes separate the ALCAPA (Alps-Carpathian-Pannonian) microplate, from the Tisza-Dacia microplate. They were separated from the European plate in the late Jurassic. The Tisza unit moved away from the European plate in the Middle Jurassic and it was contact with the Dacia microplate in the late Jurassic and Early Cretaceous-Eocene. These two tectonic units the ALPACA and Tisza-Dacia are in contact along the Mid-Hungarian line [19], [20] and [29]. The Mid-Hungarian line means a narrow fault zone but it is generally called Mid-Hungarian line see Figure 8.

The mantle structure along the Tethyan margin was investigated [21]. They also determined on average Moho depth of $25 \mathrm{~km}$. If we take into consideration [22] and [23] then this is the boundary of the magnetic crust.

The sedimentary layers of the Pannonia basin

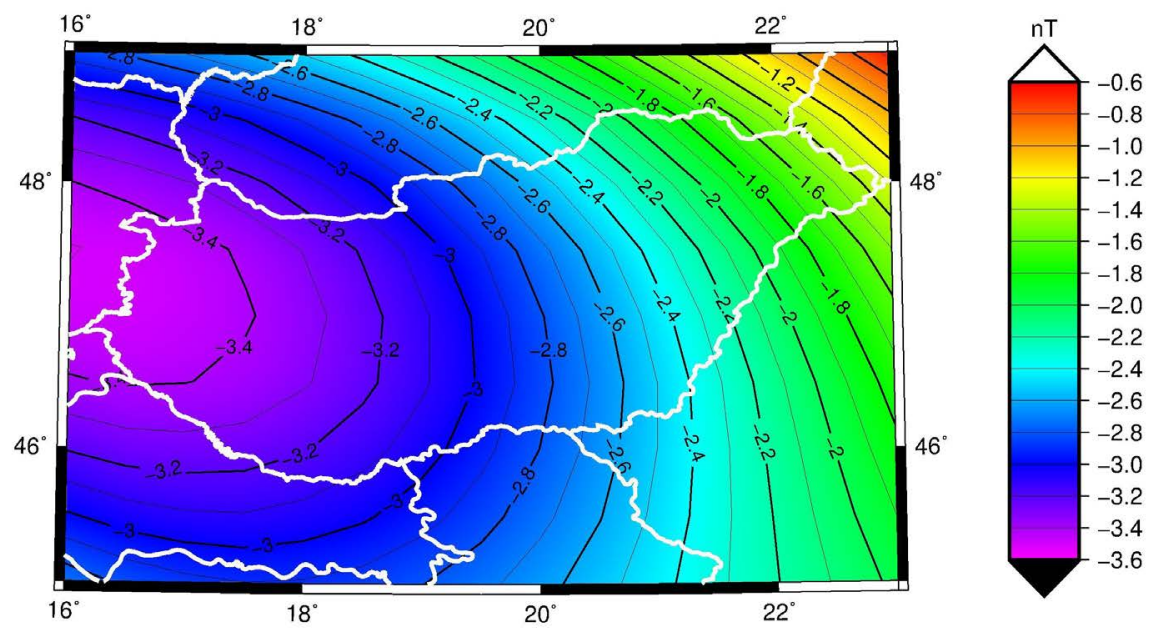

Figure 7: Total magnetic anomalies at $450 \mathrm{~km}$ altitude over the Pannonian Basin. Isolines are plotted in an Albers equal area projection. Color bar gives field in $\mathrm{nT}$.

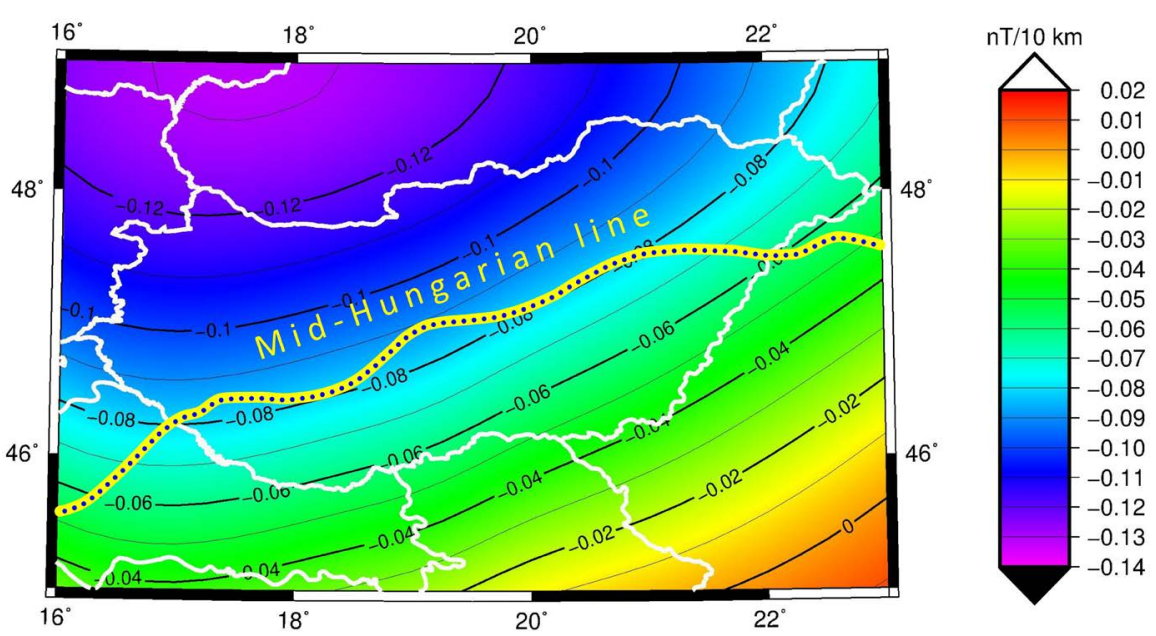

Figure 8: Vertical magnetic field gradients of the total magnetic anomalies (Figure 4) at $450 \mathrm{~km}$ altitude. The Mid-Hungarian line is highlighted. Isolines are plotted in an Albers equal area projection. Color bar gives field in $\mathrm{nT} / 10 \mathrm{~km}$. 
have average depth of $3 \mathrm{~km}$ and the relatively thin lower crust layers are characteristic of this basin [30]. The average $25 \mathrm{~km}$ Moho depth was determined by the distribution of the P-wave velocities [24]. The detailed structure of the crust was determined from the recordings of the Rayleigh waves of 17 seismologic stations [25].

Figure 7 shows the total magnetic anomalies over the Pannonian basin these anomalies represent a section of total magnetic anomalies presented in Figure 4. There is a minimum anomaly in the western part. The trend of the vertical gradient (Figure 8) in our analysis define the Mid-Hungarianline. The variation of the vertical gradient expresses the ALCAP is in a higher position.

The thermal data for the Pannonian basin are given in [17]. They find that the heat flow in the basin varies from $50-130 \mathrm{~mW} / \mathrm{m}^{2}$ with a basin-wide average of $100 \mathrm{~mW} / \mathrm{m}^{2}$, twice the global average.

The borehole temperature measured in the Pannonian Basin from 1900-5000 m can be extrapolated to deeper depths and with the Curie temperature of magnetite being $580{ }^{\circ} \mathrm{C}$ [26] then magneti- zation can be extended to $11.6-16.4 \mathrm{~km}$ the Pannonian Basin. This result is not in complete agreement with the Moho a magnetic boundary According to the cross section presented [17] after the collision of ALCAPA with the Tisza-Dacia microplates they formed the Mid-Hungarian line.

Figure 9 shows the tectonic outline of the Pannonian Basin. This map reveals the details of the tectonic elements with their directions of movement. This is a very complex region and it is difficult for satellite altitude magnetic anomalies to depict these features in detail; however magnetic measurements made by a magnetometer on the end of a tether deployed from a low Earth orbiting satellite should be able to map these complex structures [31].

\section{Error Calculation}

The error calculations are based on the Gaussian error propagation [27], and the variance of the anomalies will be described.

The position of the satellites as determined from GPS calculations has great precision so the error of

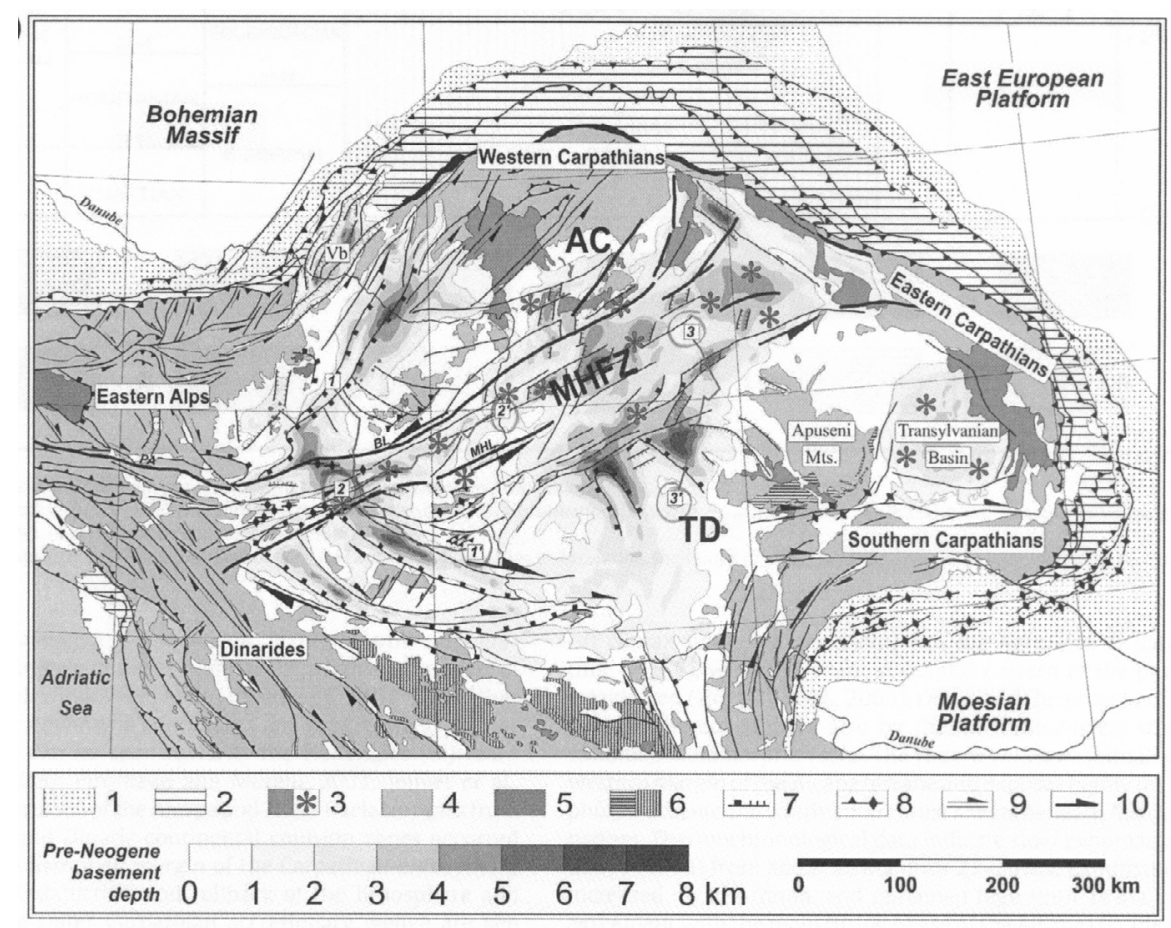

Figure 9: Map showing the depth to basement of the Pannonian Basin and the main faults controlling the basin formations. 1) Foredeeps; 2) Flysch belt; 3) Miocene volcanoes and approximate position of explosive centers erupting rhyolitic volcanoclasts; 4) Inner Alpine, Carpathian and Dinaric mountains; 5) Penninic windows; 6) West- and East-Vardar ophiolites; 7) Detachment and normal faults; 8) Thrusts and folded anticlines; 9) Strikeslip faults; 10) First order strike-slip faults; AC Alcapa terrane; MHFZ Mid-Hungarian Fault Zone; TD Tisza-Dacia terrane [17]. 
these data will be neglected. The Overhauser magnetometer also has a high precision, its dispersion is $0.4 \mathrm{nT}$. The magnetic anomalies are calculated as a difference between the measured data and the IGRF. The dispersion of the IGRF is $1 \mathrm{nT}$. The dispersion of the anomalies is $1.4 \mathrm{nT}$. Therefore, the calculated total dispersion is $1.2 \mathrm{nT}$. The two dispersions have practically the same value. The dispersion of the linear trend is $1.19 \mathrm{nT}$. The resulted dispersion $2.59 \mathrm{nT}$. The coefficients of the low-pass filter are normalized to units of one with the resulted dispersion being $2.59 \mathrm{nT}$. The coefficients of the numerical determination of vertical gradients are normalized also in units of 1 with the resulted dispersion being $0.087 \mathrm{nT} / \mathrm{km}$.

\section{Conclusions}

The total magnetic anomaly maps developed from the measurements of ESA satellite Swarm-A reflects the regional geological structure of our study area. This shows the possible application of magnetic satellite anomaly data in geological exploration. The vertical gradients clearly enhance the tectonic units. As an example, we showed the Pannonian Basin and the Mid-Hungarian line as two structures detected at $450 \mathrm{~km}$ altitude.

\section{References}

1. Taylor PT, Schnetzler CC, Regan RD (1989) Satellite magnetic data: How useful in exploration? Geophysics: The Leading Edge of Exploration 8: 26-28.

2. Taylor PT, Schnetzler CC (1990) Satellite magnetic data: The exploration industry rates their usefulness. Geophysics: The Leading Edge of Exploration 9: 4243.

3. Ravat D, Hinze WJ, Taylor PT (1993) European tectonic features observed by Magsat. Tectonophysics 220: 157-173.

4. Taylor PT, Ravat D (1995) An interpretation of the Magsat anomalies of central Europe. Journal of Applied Geophysics 34: 83-91.

5. Kis KI, Taylor PT, Wittmann G, Toronyi B, Puszta S (2012) Interpretation of the total magnetic field anomalies measured by the CHAMP satellite over a part of Europe and the Pannonian Basin. Acta Geodaetica et Geophysica Hungarica 47: 130-140.

6. Kis KI, Taylor PT, Wittmann G, Toronyi B, Puszta S (2011) Inversion of magnetic measurements of the CHAMP satellite over the Pannonian Basin. Journal of Applied Geophysics 75: 412-418.
7. Taylor PT, Kis KI, Wittmann G (2013) Interpretation of CHAMP magnetic anomaly data over the Pannonian Basin region using lower altitude horizontal gradient data. Acta Geodaetica et Geophysica 48: 275-280.

8. Abranova DYU, Filipov SV, Abranova LM, Varentsov IM, Lazovskii IN (2016) Changes of lithospheric magnetic anomalies with altitude (According to the CHAMP satellite). Geomagnetism and Aeronomy 56: 239-248.

9. DuJ, Chen C, Lesur V, Wang L (2015) Non-singular spherical harmonic expressions of geomagnetic vector and gradient tensor fields in the local north-oriented reference frame. Geoscientific Model Development 8: 1979-1990.

10.Thébault $E$, Finlay $C h C$, Beggan $C D$, Alken $P$, Aubert $J$, et al. (2015) International Geomagnetic Reference Field: the 12th generation. Earth Planets and Space 67: 79.

11.Lowes FJ (1974) Spatial power spectrum of the main geomagnetic field and exploration to the core. Geophysical Journal of the Royal Astronomical Society 36: 717-730.

12. Mauersberger P (1956) Das mittel der Energiedichte des geomagnetischen Hauptfeldes an der Erdoberflächte und seine säkulare Anderung. GerlandsBeitragezurGeophysik 65: 207-215.

13.Meskó A(1984) Digital Filtering: Applications in Geophysical Exploration for Oil. AkadémiaiKiadó Budapest 636.

14.Kis KI, Puszta S (2006) Application of the magnetic field derivatives for locating Sarmatian graves. Journal of Applied Geophysics 60: 13-26.

15.Aubouin J (1980) Geology of Europe: a synthesis. Episodes 1: 3-8.

16. Horváth F (1993) Toward a mechanical model for the formation of the Pannonian Basin. Tectonophysics 226: 333-357.

17. Horváth $F$, Musitz $B$, Balázs $A$, Végh $A$, Uhrin $A$, et al. (2015) Evolution of the Pannonian Basin and its geothermal resources. Geothermics 53: 328-352.

18.Tašárova ZA, Fullea J, Bielik M, Šroda P (2016) Lithospheric structure of Central Europe: Puzzle pieces from Pannonian Basin to Trans-European Suture Zone resolved by geophysical-petrological modeling. Tectonics 35: 722-753.

19.Csontos I, Nagymarosy A (1998) The Mid-Hungarian line: a zone of repeated tectonic inversions. Tectonophysics 257: 51-71.

20.Márton E, Fodor L (2003) Tertiary paleomagnetic results and structural analysis from the Transdanubian 
Range (Hungary): Rotational disintegration of the AlCaPa unit. Tectonophysics 363: 201-224.

21.Chang SJ, van der LeeS, Flanagan MP, Bedle H, Marone $F$, et al. (2010) Joint inversion for three-dimensional $\mathrm{S}$ velocity mantle structure along the Tethyan margin. Journal of Geophysical Research 115: B08309.

22. Wasilewski PJ, Thomas HH, Mayhew MA (1979) The Moho as a magnetic boundary. Geophysical Research Letters 6: 541-544.

23. Wasilewski PJ, Mayhew MA (1992) The Moho as a magnetic boundary revised. Geophysical Research Letters 19 2259-2262.

24.Gráczer Z, Wéber Z (2012) One-dimensional P-wave velocity model for the territory of Hungary from local earthquake data. Acta Geodaetica et Geophysica Hungarica 47: 344-357.

25.SzanyiGy, Gráczer Z, Győri E (2013) Ambient seismic noise Rayleigh wave tomography for the Pannonian Basin. Acta Geodaetica et Geophysica 48: 209-220.

26. Blakely RJ (1995) Potential theory in gravity and magnetic applications. Cambridge University Press.

27. Clifford AA (1973) Multivariate error analysis. Applied Science Publishers, London.
28. Hetenyi G, Ren Y, Dando B, Stuart G, Hegedus E, et al. (2015) Crustal structure of the Pannonian Basin: TheAlCaPa and Tisza Terrains and the Mid-Hungarian Zone. Tectonophysics 664: 106-116.

29.Sumanovac F (2015) Lithosphere model of the Pannonian-Adriatic overthrusting. Tectonophysics 665: 79-91.

30.Cloetingh S, Matenco L, Bada G , Dinu C, Mocanu V (2005) The evolution of the Carpathians-Pannonian system: Interaction between neotectonics, deep structure, polyphase orogeny and sedimentary basins in a source to sink natural laboratory Tectonophysics 410: 1-14.

31.Taylor PT, Conrad JA, Frawley JJ (1995) Expected Magnetic Field Results from a Tether Mission. Proceedings of the Fourth International Conference on Tethers In Space 2: 21245-21248.

32. Nayaud PN (1980) Derivation, Meaning and Use of Geomagnetic Indices. AGU Geophysical Monograph 22.

33.Langel R, RH Estes (1982) A Geomagnetic Field Spectrum. Geophysical Research Letters 9: 250-253.

34.Arkani-Hamed J, Urquhart W, Strangway D (1985) Scalar magnetic anomalies of Canada and northern united states derived from Magsat data. Journal of Geophysical Research 90: 2599-2608. 